\title{
The Role of Social Media Technologies in Service Innovation: Perceptions of Exceptional-customer-engaged Value Co-creation*
}

\author{
Yao $\mathrm{Wu}$ \\ Sun Yat-sen University \\ wuyao3@mal2.sysu.edu.cn
}

\author{
Jinghua Xiao \\ Sun Yat-sen University \\ $\underline{\operatorname{lnsxjh} @ \text { mail.sysu.edu.cn }}$
}

\author{
Kang Xie \\ Sun Yat-sen University \\ mnsxk@mail.sysu.edu.cn
}

\begin{abstract}
Social media technologies have greatly facilitated customers' self-empowerment, and have given rise to a handful of exceptional customers who engage in service innovation. Compared with the more common customer behaviors like word-of-mouth and reviewand-feedback, exceptional customers actively integrate their heterogeneous resources and creatively cooperate with firms to innovate service. Nevertheless, there have been relatively few studies on how information technologies enable such customer engagement and the co-creation of service innovation. We adopted a qualitative approach and conducted a comparative analysis of two cases, including a pair of firms and their cooperating exceptional customers, to reveal two value co-creation mechanisms enabled by social media technologies: customers as communicators who facilitate the individualization of product promotion through resource sharing and digital engagement with firms; and customers as innovators who facilitate the individualization of brand design through resource convergence and co-creation of new value propositions with firms. This study discovered the enabler role of social media technologies in service innovation and value cocreation between firms and exceptional customers, as well as a theoretical basis and practical guidance for market innovation in the digital era.
\end{abstract}

\section{Introduction}

Technological innovation such as social media has radically transformed the ways through which customers come into contact with products and brands. Conventionally, customers usually obtained product information through searches after a definite need had arisen; however, social referrals have now become an important means through which customers obtain new product or brand information. Despite not knowing what they want, customers naturally develop purchasing needs and transaction behaviors through social interactions [23]. Such transformation has largely fostered a substantial revolution in marketing from traditional "push advertising" and "search-based e-commerce" to "social commerce".

In particular, more attention should be paid to exceptional customers who have developed extensive marketing influence through social interactions. They are empowered by social media technologies [21] and usually possess heterogeneous personal resources that are distinct from firm-owned resources [16]. For instance, they are more familiar with the needs of niche communities, able to engage in direct inter-personal interactions and can develop creative interpretations of existing products and brands [12]. More importantly, average customers are more willing to trust their recommendations than firms [36].

Social media technologies support exceptional customers in embarking on individualization and unlocking enormous business potential in marketing interactions [30]. When it comes to academic research, however, despite customer engagement being a longstanding subject of importance in marketing studies [7, 17], insufficient attention was given to how technologies enable customers engage in service innovation. In addition, although existing studies called for the understanding of service innovation based on the service-dominant logic [2, 24], most of them kept the emphasis on the dominant role of firms in resource integration and of service innovation. There were relatively few discussions in existing studies about how customers co-create value with firms for service innovation when they are empowered by technologies and become the dominant group in the allocation of social network resources.

Using customer-initiated social commerce as the research context is eminently suitable for exploring this question, which is clearly distinct from firm-initiated social commerce and refers to a business model in which individual customers leverage interpersonal influence based upon their social networks to initiate or facilitate transactional interactions [20,27]. It mainly occurs when transactional applications and services are added to original social networks (such as Facebook, LinkedIn, and WeChat) to help users engage in business communication and activities with ease. 
This study was exploratory in nature and mainly adopted a qualitative approach. Through interviewing two firms and their cooperating exceptional customers, a comparative case study design was adopted to reveal the differentiated value co-creation mechanisms. A detailed description of the cases was given to crystallize the effects of customers' resource contribution on their formation of differentiated roles and dissect the impact of social media technologies in enabling exceptional customer engagement and value co-creation mechanisms.

\section{Theoretical background}

\subsection{Service innovation}

In this study, service innovation was interpreted under the theoretical framework of service-dominant logic $[24,34,35]$. The design of this study was mainly based on two core characteristics of this theoretical framework. It highlights that services are fundamental to the economic exchange between firms and customers [34, 35]. It defined services as the application of specialized competences by an entity for enhancing the benefit of another entity or itself [34, 35]. The service-dominant logic sees all actors as resource integrators in actor-to-actor networks [15, 24]. In this study, service innovation was defined under the service-dominant logic as "a new service or such a renewal of an existing service co-developed and put into practice jointly by firms and customers." This concept emphasizes that service innovation originates from value co-creation between firms and customers and highlights their cooperation as an important process for achieving service innovation.

Most studies maintained their emphasis on the dominant role of firms in resource integration and the facilitation of service innovation [22]. This implied that firms are the main resource providers in service innovation and reflected the implicit assumption in existing research that "firms are service providers, and customers are participants in value co-creation". Less attention was devoted to customers who actively integrate resources, engage in service co-creation, or even create service.

\subsection{The role of social media technologies in service innovation}

In the existing literature of marketing and IS, information technology is considered to be an important factor in enabling value co-creation between firms and customers and facilitating service innovation $[24,29]$. In the context of social commerce, this study focuses on social media technology, one of the most important information technologies that empowers customers to be the center of online transaction [9]. As social media technologies supporting user sharing and user generating [3], customers can be the creators or the distributors of resource online instead of the receivers who passively accepting information. Besides, social media technologies have evolved from purely customer-specific tools to customer-centric applications, enabling firms to engage in consumers' network [33]. This provides technological conditions for the value cocreation. Previous research shows that social media technologies can enhance interactions, enabling business partners and customers to cooperate, create new business models and explore new approaches to create value [27]. Firms try to combine social media with the sales technologies to create deeply-collaborative interactions with customers [25] and communicate quickly and intensively with them [1]. As the above research, although technological factors have been repeatedly mentioned, and the value of social media technology has been unanimously recognized by scholars, the internal mechanism of how social media technology facilitates customers' engagement in service innovation and value cocreation with firms has been less thoroughly discussed.

\subsection{Empowerment and exceptional customers}

Social media technologies significantly reinforce individual customers' utilization of social networking resources, promote inter-group interactions, and enhance the interpersonal influence, thus giving rise to consumer empowerment [18,21]. The diversity of resources owned by individual customer determines his/her influence within the social network and the value to engagement [37]. In this study, we focused on customer engagement in marketing and divide customers into two general categories: exceptional customers who own heterogeneous personal resources that differ from firm-owned, thus showing significant influence on other customers' purchasing decisions, and average customers who are susceptible to others rather than influencing others.

Existing research believed that exceptional customers possess some combination of four separate yet interrelated and highly-valuable resources [16]: customer network assets, referring to the number, diversity, and structure of a customer's interpersonal ties within his or her social network; customer persuasion capital, referring to the degree of trust, goodwill, and influence a customer has with other existing or potential customer; customer knowledge stores, representing a customer's accumulation of knowledge about the product, brand, firm and other customers [8]. Finally, customer creativity is a 
customer's “production, conceptualization, or development of novel, useful ideas, processes, or solutions to problems" [20].

Customer-owned resources underlie customer engagement in marketing. Examples include opinion leaders who promote products through knowledge contributions [4]. Another example is connectors who exert their marketing influence through structural social capital [31]; they include customers with an extensive social network or individuals who serve as key nodes in the social network.

\section{Research Method}

We employed a case study methodology to explore how social media technologies enable exceptional customer engagement and the co-creation of service innovation between firms and exceptional customers. The research question and its background articulated in the previous sections support a case study methodology for this research, given the lack of extensive academic studies [6]. Besides, the interaction between firms and exceptional customers occurs in complex and dynamic processes. Case study helps us discover and explicate key concepts and relationships in such complex phenomena [13], and develop a theoretical model that is grounded in the analysis of those concepts and relationships.

A two-case design was adopted in this study. The preliminary survey of six firms revealed that two market service strategies were generally formed in their cooperation with exceptional customers: individualized product promoting and individualized brand construction strategies. This early finding allowed this study to further focus on how firms cooperate with exceptional customers to realize the two different strategies for marketing service innovation and on the various value co-creation mechanisms involved. To explore this subject, two out of the six firms enrolled in the preliminary survey were selected for further analysis. They were two completely independent firms that belonged to the same group and implemented each of the two marketing strategies described above, thus presenting a stronger contrast.

The research team adopted three different sources of evidence-semi-structured interview, files, and observations - to enable the triangulation and complementarity of data. As highlighted by Yin [39], no single source of evidence can completely overshadow the other sources; all sources have their advantages and are complementary to one another. Table 1 shows the information about data collection.
Table 1. Data sources and profile of interviews

\begin{tabular}{ll}
\hline Case & \multicolumn{1}{c}{ Descriptions of Interviewees } \\
(Number of Interviews)
\end{tabular}

To support data analysis of the comparative case study design, we adopt the procedures recommended by Yin [39] and Eisenhardt [6] that conducted single case analysis first and then made comparative analysis. The open coding strategy and the axial coding strategy were used throughout the analysis. To ensure credibility of the data, we took several well-established techniques outlined and utilized by Silverman et al.[28], Friend and Malshe [10] and Johnson and Sohi [19]. 


\section{Research Findings}

\subsection{Case A}

In this case, Company A was a leading fashion brand specializing in South Korean fast fashion; it had enormous product R\&D capabilities and developed 30,000 new products every year. Its product collection had extended to include 12 categories such as bags and cases, shoes, and underwear. Such product R\&D capabilities had presented a higher demand on its marketing capabilities. To improve their marketing effectiveness, Company A tried to cooperate with community gurus (the exceptional customers in Case A, who had considerable interpersonal influence in niche communities), in hope of matching with the target customers precisely and attracting new customers. Based on the data analysis of Case A, this study identified two important mechanisms behind the value co-creation:

Resource Sharing. Resource sharing refers to that the parties share their heterogeneous resources to achieve certain goals, so that partners can use these resources conveniently or share the benefits of resource use. In Case A, the community gurus cooperating with Company A mainly share three types of heterogeneous resources that are distinct from firm-owned resources, including network assets, persuasion capital, and knowledge stores. Interestingly, even before working with Company A, many community gurus would also leverage these resources for product recommendations to influence the purchasing decisions of other customers in their social networks. Nevertheless, there are apparent limitations in this practice: they generally lack production capability and tend to profiteer by reselling products purchased from various outlets, which makes it difficult to control the product quality.

Company A mainly shared its product resources to compensate for these gurus' shortcomings in product supply. This included the provision of operand resources such as ready-to-wear products, which allowed the community gurus to choose from the products already launched by Company A's flagship; Company A could then quickly promote the existing products of the brand. The shared resources also included operant resources, such as support for product R\&D based on the need of each community; in light of this, Company A optimized the organizational structure in R\&D and established "product teams" devoted to serving each niche community. Each product team interacted closely with the corresponding community gurus and assimilated their understanding of community needs and feedback about product sale, thus achieving targeted product improvement or optimization of new products.
Digital Engagement. To enhance the overall exposure of products and allow a large variety of products to penetrate various communities, Company A developed marketing cooperation dominated by virtual interactions with multiple community gurus. It is summarized as digital engagement, which refers to virtual communication and cooperation behaviors through which the parties make voluntary resource contributions, manifesting in two aspects:

The first is that Company $\mathrm{A}$ and exceptional customers engaged in the co-creation of online virtual characters through digital approaches. They collectively develop a role called the "online fashion stylist," which focused on providing community customers with online consultancy services for outfit matching. The community gurus shared their personal WeChat accounts with Company A, and Company A created image-and-text links affiliated with different online stylists and post them through various digital marketing channels. Using these links, average customers could directly establish interpersonal connections with the online stylists.

The second aspect of digital engagement is Company A and exceptional customers engaged in the co-creation of interactive marketing channels through digital platforms. For example, marketing and promotions were carried out through digital media outlets such as social network platforms and livestreaming technologies. Community gurus promoted and sold products personally through third-party social networking sites. They periodically selected 3-5 products from new in-season items to mix and match an outfit, and then put on for individualized photo shoots. Company A evaluated the marketing effectiveness based on sale information returned by the product links and improved the promotional channels and approaches adopted by the community gurus.

During the process of customer engagement and value co-creation, social media technologies facilitated the value co-creation between Company $\mathrm{A}$ and community gurus and constituted an important technological basis for achieving resource sharing and digital engagement. Two technological characteristics are manifested in this case: enabling connectivity and enabling interactivity.

Enabling Connectivity. The connectivity of social media technologies indicates the technical features that creating interconnectivity among individuals and organizations who are originally separated by time and space. Our case shows that this connectivity feature has supported the heterogeneous resource sharing and digital engagement. For instance, the instant messaging feature embedded in these technologies allowed employees to share the latest product informationprofessional graphical and textual information such as 
the materials and colors of new products - with the cooperating gurus anytime and anywhere. Company A and community gurus could conveniently exchange information resources. This provides technological support for community gurus to become the communication media connecting average customers with Company A. Moreover, social media technologies allowed Company A and community gurus to perform digital virtual interactions in online spaces and overcome spatio-temporal constraints. This way, both individuals and organizations can share digital resources (such as product photos) in a quick and convenient way. On the other hand, the connectivity of social media technologies also allowed Company A to establish resource connections with community gurus dispersed across different geographies. This is especially helpful for Company A in creating product promotions targeted at different communities quickly.

Enabling Interactivity. Our case analysis revealed that the interactivity of social media technologies supporting the exchange of information or resources between firms and their cooperating customers facilitated the quick and convenient storage and transmission of information resources. When Company A was sharing graphical and textual information about new product recommendations and interacting through text and audio with community gurus, such information could be stored instantly in WeChat's back-end cloud server and viewed and downloaded anytime within three days, thereby enhancing the accessibility of information resources to the participants of such cooperation. It also allowed multiple community gurus to access the same information anytime and anywhere.

With regard to the interactive behavior of the community gurus, such interactivity has given them quick access to the right to use digital images and texts, thus enhancing their resource convergence and engagement in marketing interactions. Some community gurus would download the graphical and textual information shared by the firm and post it to their WeChat Moments along with pictures of themselves posing in the same clothes, their outfit advice, or creative statements about that type of clothes. This showcased the role of such interactivity in encouraging users to generate virtual content.

On the other hand, the interactivity of social media technologies is also manifested in how they give Company A and community gurus quick and easy access to interactive information. This allows both parties to interact and communicate across spatial and temporal boundaries, thus facilitating more flexible online product promotions.

The case analysis revealed that the resource sharing and digital engagement between Company A and exceptional customers enabled by social media technologies have facilitated the individualization of product promotions, which is an important type of service innovation in marketing. The collective innovation of product promotion services improved shopping experience perceived by existing and prospective customers during product exposure.

\subsection{Case B}

Compared with Company A, Company B in Case $B$ adopted an entirely different strategy and pathway for realizing service innovation with exceptional customers. Case B demonstrated that firms can enhance the individualization of brand design by allowing exceptional customers engage in brand construction by leveraging their unique creativity. Company B was a corporate group operating an online brand ecosystem. It integrated the parent company's near-decade experience in operating Internet brands and possessed organizational resources that supported multi-brand operations. It was mainly committed to developing new brands and realizing long-term innovative development. An important means for developing new brands was to cooperate with individual customers in constructing original brands. Company $\mathrm{B}$ regarded individual customers with unique creativity as innovator for building original brands fitted to the needs of niche communities. Based on the data analysis of Case B, this study identified two important mechanisms behind brand constructionoriented value co-creation:

Resource Convergence. Company B was inclined to work with individual customers with unique creativity and market insights. These exceptional customers usually penetrated niche markets through their own designs or product creations and had unique personal experiences with such markets. Despite owning an abundance of heterogeneous resources, such exceptional customers still find it difficult to build a brand entirely relying on their personal resources. Therefore, Company B and exceptional customers integrated their heterogeneous resources consistently to form new resources for brand construction, designing new products or services collectively. We conceptualized the collective behaviors as resource convergence, specifically referring to the participants reorganized resources to create new resources for breaking through the limitations of their respective resources.

Taking the cooperative development of industryspecific products (such as agricultural specialties with regional characteristics) as an example. Company B would fully respect professionalism of the cooperating customers in product design and production, and adjust 
resources such as product packaging design and thirdparty logistic to match new product development. An employee from Company B's general manager office gave the following example:

"We cooperated to build a successful original brand specializing in selling Hosui pears. These pears sold well because he (EC) used natural resources specific to his home town and a farming technique researched, developed, and modified by himself. This improved the texture substantially, and the pears taste silky-smooth like milk. He spent three years handpicking the seed variety and plantation location and invented the 'milk + brown sugar + white sugar' golden-ratio fermentation. We must certainly respect such professionalism and adjust more of our resources in packaging, logistics, and promotion."

Co-creation of new value propositions. The case analysis revealed that to fit community needs precisely requires the synergistic effects between exceptional customers' personal judgement of new value propositions and Company B' organizational experience in brand construction. The exceptional customers shared their unique experience with Company B; meanwhile, Company B assigned employees with brand-building experience to discuss and condense such niche needs, thus forming certain solutions for each value proposition. The solutions are then validated and finalized through market research. A vivid example was cited by Company B's production center director:

"The online celebrity who made long dresses knew why some shorter women prefer maxi dresses despite their height. According to her, some fans told her that they had a wider crotch and crooked legs and that long dresses could cover these features better. Not a lot of customers would tell companies things like that. If we were to guess, we might assume that long dresses are only favored by taller women, but that is far from the truth. On the contrary, many shorter women opt for long dresses. Influencers (ECS) can provide a more unique interpretation of the underlying reasons for such a preference. We transform such experience together to see if any of that can be applied to our brand positioning and what kind of description is more fitting to the fans' mindsets. In this case, we eventually finalized the brand slogan as 'a long dress can change a girl's destiny.' The outcomes were very successful judging from the fan conversion rate."

The analysis of Case B revealed that the two other characteristics of social media technologies - enabling exploration and enabling coordination-play a pivotal role in achieving heterogeneous resource convergence and the co-creation of new value propositions.

Enabling Exploration. The exploratory feature of social media technologies refers to the technical features for absorbing new information or other resources, which in our case significantly helped Company B and exceptional customers to build their own heterogeneous resources. For example, exceptional customers made use of social media technologies to absorb differentiated information from communities that was distinct from firm-owned information; this allowed them to develop heterogeneous resources in the forms of knowledge and creativity. When cooperating with these customers in new product design, Company B also applied social media technologies to the market testing of innovative products or services. For example, new brands constructed in cooperation with exceptional customers were first tested in a small-scale online community; the fans' interactions and feedback as well as the market fit were analyzed to identify any unknown issues, so as to design and improve the brands.

Technological connections with social media platforms also facilitated the precise data management of Company B and supported efficiently in determining whether a new brand was suited to the needs of niche markets. For instance, Company B measured the sales of stock keeping units in real time using the group's big-data "FMSN" system (a production decisionmaking system based on a decision-making algorithm) with reference to data obtained from social media platforms, such as item sales and users' behavior. Each item was then ranked according to various data dimensions and categorized as fast-moving, mediummoving, slow-moving, or non-moving items. New orders were placed to manufacture more of the fastand medium-movers, whereas the slow- and nonmoving items would be discounted for clearance. Meanwhile, the development of different new brands was also evaluated through horizontal comparison of their brand data. This facilitated the design and improvement of new brands tremendously.

Enabling Coordination. According to the case analysis, the coordination between Company B and exceptional customers is also enabled by social media technologies. This includes internal coordinationresource convergence and interaction between the firm and exceptional customers-and external coordination - the adaptability of the firm and exceptional customers, as a system, to changes in the external market environment.

From the perspective of internal coordination, social media technologies allow Company B and exceptional customers to jointly design the brand value by facilitating their dyadic interactions. For instance, Company B would create a WeChat group with its cooperating customers and add all relevant parties responsible for the brand construction and operations to that group, where they could share and exchange 
ideas and design solutions about brand innovation and adjust their thinking. At the same time, WeChat offers basic social functions such as group video chat and voice call and supports online conferencing, which significantly facilitates multi-participant interactions.

As for external coordination, exceptional customers adopt social media technologies to develop fan communities and understand their experience and feedback about new products in real time. In doing so, they accumulated personal experience that could be applied to the R\&D decision-making for new products or planning of new marketing services. To understand the market dynamics promptly, Company B made use of its big data application platform to connect with external social platforms. This allowed it to capture and collect market and community big data in real time and conduct dimensional analysis precisely, in turn enhancing the coordinated decision-making among departments.

Based on the analysis, the case study revealed that the resource convergence and co-creation of new value propositions between the firm and exceptional customers enabled by social media technologies have facilitated the individualization of brand design.

\subsection{Cross case analytics}

Comparative analysis discerned striking similarities and intriguing differences between the cases, manifested mainly in five aspects: customer resources, role of customers, co-creation mechanism, technological influence, and outcomes of co-creation.

The case analysis indicated two distinct roles of customer-owned resource in promoting customer engagement in service innovation, one of which was dominant resources - that have a decisive influence on the role and behavior of customers during engagement. The second dimension was collaborative resources, which meant resources supporting the dominant resources at play. All exceptional customers in both Case A and Case B were required to have knowledge stores, so that they could provide average customers with individualized outfit advice or share their unique experience about the needs of niche markets with firms. It was with these knowledge resources that they were able to attract more customers (network assets) and gain more trust from them (persuasion capital) or develop unique creativity through knowledge accumulation and innovation (creativity). This reveals the interrelated relations of these four resources.

As for the role of customers, in both cases, the firms embarked on in-depth value co-creation with exceptional customers. Under the influence of the differentiated service innovation strategies adopted by firms, the exceptional customers in Case A served as communicators connecting the firm with average customers and used their network assets and interpersonal communication skills to initiate individualized community marketing; the exceptional customers in Case B served as innovators helping the firm in co-creating new brands and leveraged their unique creativity to co-create original brands suited to the needs of niche communities, offering differentiated and individualized brand designs.

In terms of value co-creation mechanism, this study further segments the resource integration mechanisms according to the different service innovation strategies. In Case $A$, the two main mechanisms adopted to enable product promotion individualization were resource sharing and digital engagement. The former aimed to overcome the limitations of unilateral-owned resources. Digital engagement enabled the rapid realization of widespread and low-cost product promotions involving multiple participants; it allowed the firm to work with the many community gurus dispersed across various social networks in a quick and easy manner. In Case B, the primary mechanisms adopted to facilitate individualized brand construction were resource convergence and the co-creation of new value propositions. The former shed light on how two parties could co-create new brand resources through effective resource alignment, whereas the latter accentuated the need for firms and exceptional customers to resonate with fans through resource convergence.

In terms of technological influence, both cases demonstrated that social media technologies significantly enhanced value co-creation and, consequently, facilitated service innovation. However, the four technological characteristics-enabling connectivity, interactivity, exploration, and coordination-exerted different impacts on various value co-creation mechanisms. In the mechanism where exceptional customers served as communicators, the connectivity and interactivity of technologies enabled the resource sharing and digital engagement. In the mechanism where exceptional customers served as innovators, the enablement of exploration and coordination by social media technologies facilitated the resource convergence and co-creation of new value propositions. This conclusion revealed the differentiated effects of social media technologies on enabling different types of service innovation as well as the underlying mechanisms.

In terms of the outcomes of co-creation, in both cases, the renewal of existing services was achieved through value co-creation between firms and exceptional customers. Nevertheless, the specific outcomes varied: in Case A, the firm cooperated with exceptional customers as communicators in product 
promotions to improve shopping experience perceived by existing and prospective customers; it also renewed marketing services through recreational community marketing and interactions. In Case $B$, the firm cooperated with exceptional customers as innovators in designing and building original brands; by integrating personal and organizational resources, they proposed new value propositions affiliated to the brands, achieving service renewal for the existing communities by means of individualized brand design.

Based on the above analysis, this study developed a theoretical framework of the value co-creation between firms and their cooperating customers in marketing service innovation, as shown in Figure 1.
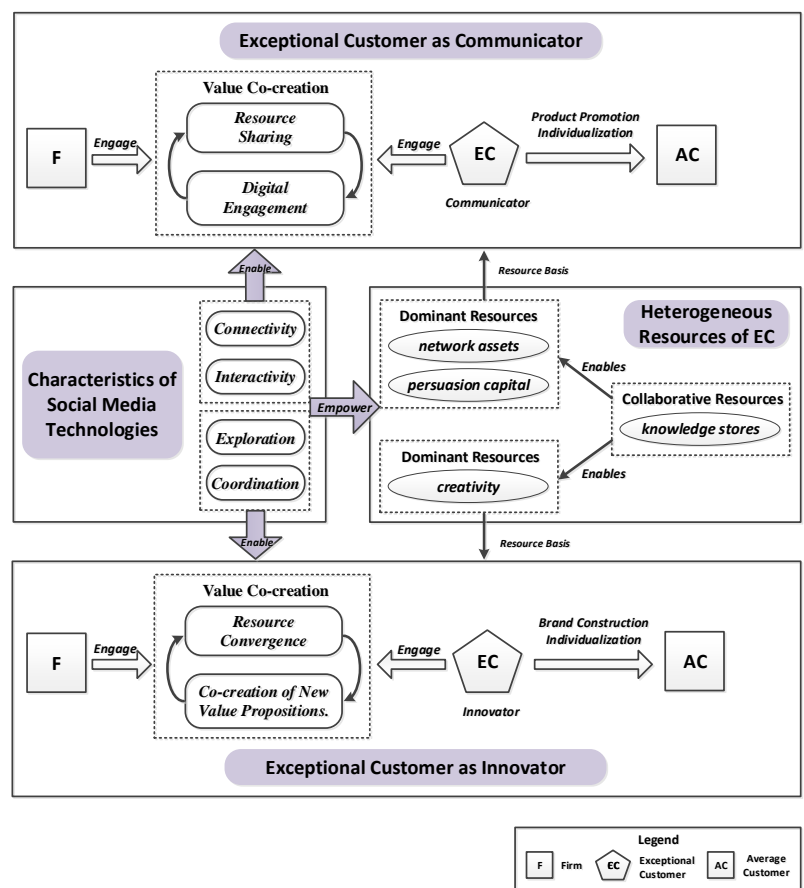

Figure 1: A theoretical framework of IT-enabled service innovation co-created by firms and exceptional customers

\section{Discussion}

\subsection{Theoretical implications}

This study focused on how social media technologies enable exceptional customer engagement and the co-creation of service innovation between firms and their cooperating exceptional customers. We believe this study advances extant research in at least three ways.

First, this study reveals how social media technology empowers exceptional customers to engage in service innovation from a customer-owned resource perspective. Social media technologies empowering customers have long been used as a premise to interpret changes in customer status and behaviors in the digital age [9, 21]. However, what aspects of customers are changed and how they are changed by social media technologies, that trigger transformation of customer status and behaviors, have been little explored. This study advocates an in-depth understanding of social media technologies' value in service innovation for exploring such question. Our research findings show that 1) social media technologies have dramatically altered the ways through which exceptional customers connect with firms and average customers, and has utterly disrupted the isolation among customer groups and overturned the resource limitations faced by individual customers, promoting the emergence of unique customer groups in social commerce; 2) four characteristics of social media technologies, including connectivity, interactivity, exploration and coordination, empower exceptional customers to have heterogeneous resources that distinguish from firm owned and average customer owned. Our findings provided rich vivid illustrations for consumer empowerment enabled by social media technologies and introduced a value co-creation concern based on the existing studies which mainly pay attention to consumer behaviors and their impacts in empowerment $[5,21]$.

Second, this study uncovers the role of social media technologies in service innovation. Although technological factors have been repeatedly mentioned in service innovation research [22, 32, 38], the mechanism of how such emerging technologies enables service innovation has been little explored. By focusing on the context of customer-initiated social commerce, our findings show that social media technologies facilitate service innovation by enabling the integration of heterogeneous resources between firms and their cooperating exceptional customers. The stronger the heterogeneity of resources is, the more likely it will stimulate the creation of new values, thus facilitating service innovation. Besides, as indicated by the existing research, service innovation is motivated through interaction [26]. Our study shows the significance of social media technologies in enabling the interaction between firms and exceptional customers in co-creating service innovation.

Third, this study enriches the theoretical perspective on how firms and exceptional customers co-create service innovation in the digital age. Existing studies posited that service innovation stems from the renewal of value propositions generated when firms deliver resources to improve customers' own value creation [22]. Less attention was given to customers who actively provide heterogeneous resources for 
value creation, as well as how these exceptional customers cooperate with firms to innovate service. This study proposes that social media has fundamentally transformed the constraints restricting exceptional customers engaging in the innovation with firms. Firms are required to leverage exceptional customers in establishing interpersonal trust to quickly penetrate niche communities, whereas the exceptional customers need organizational resources to sustain their marketing influence. If either of them is absent in this service innovation process, the service effectiveness will be impeded by the limited resources and capabilities. Our study also reveals two kinds of value co-creation mechanisms enabled by social media technologies for service innovation: customers as communicators who facilitate the individualization of product promotion through resource sharing and digital engagement with firms; and customers as innovators who facilitate the individualization of brand design through resource convergence and co-creation of new value propositions with firms.

\subsection{Managerial implications}

This study yielded insights about the pathways through which firms cooperate with exceptional customers based on social media technologies to initiate management practices for marketing service innovation. Specifically, when attempting to create product promotions targeted specifically at niche communities, managers should consider exceptional customers with enormous network assets and persuasion capital as communicators. During such cooperation, firms should provide their resources, such as professional logistic delivery or special-design packaging, compensating the shortage of customer resources in individualized product promotions. In another case, when managers are attempting to construct original brands targeted at niche communities, they should position exceptional customers with creative resources as innovators and allow them to contribution their creativity to brand construction. For this goal, firms and their cooperating customers should reorganize existing resources to develop new value propositions suited to the needs of niche markets.

\subsection{Limitations and future research}

As an exploratory case study, it contained three main limitations: firstly, two sample firms that adopted product promotions and brand construction as their respective strategies for marketing service innovation were selected. Differences in such strategies may affect the distinct roles of exceptional customers in customer engagement and the value co-creation mechanisms.
However, we could not exclude the existence of other customer roles and relevant mechanisms. More cases should be added in the future research to advance this discussion. Secondly, as conducting a comparative two-case study, the focus of this paper is to discover the most significant difference between two value cocreation mechanisms. However, we admit the intersection of the two proposed mechanisms, such as resource sharing and resource convergence may be able to be observed in both cases. Paper length limits our further discussion of this issue, so we cannot explain in detail what is the relationship between resource sharing and resource integration, as well as the differences of their imparts on the two value cocreation mechanisms. We believe this question is deserved to be explored and solved in future studies. Thirdly, the major focus was placed on social media technologies; in reality, however, many other technologies such as the big data analytics of firms also play a crucial role in cooperation. Future research will incorporate a discussion on the mechanisms of technological influence to offer more interesting and valuable conclusions on how firms can advance value co-creation through the use of technologies.

\section{Footnotes}

*This research is funded by research grants from National Natural Science Foundation of China (Grant \# 71832014, 71771223 and 71802204) and China Postdoctoral Science Foundation (Grant \# 2019T1120785). Kang Xie is the corresponding author.

\section{Reference}

[1] Agnihotri, R., K.J. Trainor, O.S. Itani, and M. Rodriguez, "Examining the Role of Sales-based CRM Technology and Social Media Use on Post-sale Service Behaviors in India", Journal of Business Research 81(August), 2017, pp. 144-154. [2] Barrett, M., E. Davidson, J. Prabhu, and S.L. Vargo, "Service Innovation in the Digital Age: Key Contributions and Future Directions", MIS Quarterly 39(1), 2015, pp. 135154.

[3] Berthon, P., L. Pitt, J. Kietzmann, and I.P. McCarthy, "CGIP: Managing Consumer-Generated Intellectual Property", California Management Review 57(4), 2015, pp. 43-62.

[4] Van Den Bulte, C., and S. Wuyts, Social Networks and Marketing, Cambridge, MA: Marketing Science Institute, 2007.

[5] Denegri-Knott, J., D. Zwick, and J.E. Schroeder, "Mapping Consumer Power: An integrative framework for marketing and consumer research", European Advances in Consumer Research 40(9/10), 2006, pp. 950-971.

[6] Eisenhardt, K.M., "Building Theories from Case Study Research.", Academy of Management Review 14(4), 1989, pp. 532-550. 
[7] Etgar, M., "A Descriptive Model of the Consumer Coproduction Process", Journal of the Academy of Marketing Science 36(1), 2008, pp. 97-108.

[8] Feick, L.F., and L.L. Price, "The Market Maven: A Diffuser of Marketplace Information", Journal of Marketing 51(1), 1987, pp. 83-97.

[9] Foltean, F.S., S.M. Trif, and D.L. Tuleu, "Customer Relationship Management Capabilities and Social Media Technology use: Consequences on Firm Performance", Journal of Business Research(October), 2018, pp. 1-13.

[10] Friend, S.B., and A. Malshe, "Key Skills for Crafting Customer Solutions Within an Ecosystem: A Theories-in-Use Perspective", Journal of Service Research 19(2), 2016, pp. 174-191.

[11] Fyrberg Yngfalk, A., “'It's not us, it's them!' Rethinking Value Co-creation among Multiple Actors", Journal of Marketing Management 29(9-10), 2013, pp. 1163-1181.

[12] Goldsmith, R.E., L.R. Flynn, E.B. Goldsmith, et al., "Innovative Consumers and Market Mavens", Journal of Marketing Theory and Practice 11(4), 2003, pp. 54-65.

[13] Graebner, M.E., and K.M. Eisenhardt, "The Seller' s Side of the as Story: Acquisition and Courtship as Governance in Syndicate Firms Entrepreneurial”, Administrative Science Quarterly 49(3), 2013, pp. 366-403.

[14] Grönroos, C., "Conceptualising Value Co-creation: A Journey to the 1970 s and Back to the Future", Journal of Marketing Management 28(13-14), 2012, pp. 1520-1534.

[15] Grönroos, C., and P. Voima, "Critical Service Logic: Making Sense of Value Creation and Co-creation", Journal of the Academy of Marketing Science 41(2), 2013, pp. 133150 .

[16] Harmeling, C.M., J.W. Moffett, M.J. Arnold, and B.D. Carlson, "Toward a Theory of Customer Engagement Marketing", Journal of the Academy of Marketing Science 45(3), 2017, pp. 312-335.

[17] Hollebeek, L.D., R.K. Srivastava, and T. Chen, "S-D logic-informed Customer Engagement: Integrative Framework, Revised Fundamental Propositions, and Application to CRM", Journal of the Academy of Marketing Science, 2016, pp. 1-25.

[18] Hsieh, S.H., T.H. Tseng, and C.T. Lee, "Drivers of Online Brand Community Value Creation: The Role of Psychological Empowerment”, 9, 2018, pp. 2120-2129.

[19] Johnson, J.S., and R.S. Sohi, "Understanding and Resolving Major Contractual Breaches in Buyer-seller Relationships: A Grounded Theory Approach", Journal of the Academy of Marketing Science 44(2), 2016, pp. 185-205.

[20] Kozinets, R. V., A. Hemetsberger, and H.J. Schau, "The Wisdom of Consumer Crowds: Collective Innovation in the Age of Networked Marketing", Journal of Macromarketing, 2008.

[21] Labrecque, L.I., J. vor dem Esche, C. Mathwick, T.P. Novak, and C.F. Hofacker, "Consumer power: Evolution in the digital age", Journal of Interactive Marketing 27(4), 2013, pp. 257-269.

[22] Lehrer, C., A. Wieneke, J. vom Brocke, R. Jung, and S. Seidel, "How Big Data Analytics Enables Service Innovation: Materiality, Affordance, and the Individualization of
Service", Journal of Management Information Systems 35(2), 2018, pp. 424-460.

[23] Liang, T.-P., Y.-T. Ho, Y.-W. Li, and E. Turban, "What Drives Social Commerce: The Role of Social Support and Relationship Quality", International Journal of Electronic Commerce 16(2), 2011, pp. 69-90.

[24] Lusch, R.F., and S. Nambisan, "Service Innovation: A Service-Dominant-Logic perspective", MIS Quarterly 39(1), 2015, pp. 155-175.

[25] Marolt, M., A. Pucihar, and H.-D. Zimmermann, "Social CRM Adoption and its Impact on Performance Outcomes: a Literature Review", Organizacija, 2015.

[26] Miles, I., "Patterns of Innovation in Service Industries", IBM Systems Journal 47(1), 2008, pp. 115-128.

[27] Nath, P., S. Nachiappan, and R. Ramanathan, "The Impact of Marketing Capability, Operations Capability and Diversification Strategy on Performance: A Resource-based View", Industrial Marketing Management, 2010.

[28] Silverman, D., and A. Marvasti, Doing qualitative research: A comprehensive guide., Sage Publications, 2008.

[29] Srivastava, S.C., and G. Shainesh, "Bridging the Service Divide Through Digitally Enabled Service Innovations: Evidence From Indian Healthcare Service Providers.", MIS Quarterly 39(1), 2015, pp. 245-A19.

[30] Stephen, A.T., and O. Toubia, "Deriving Value from Social Commerce Networks", Journal of Marketing Research 47(2), 2010, pp. 215-228.

[31] Sutanto, J., C.H. Tan, B. Battistini, and C.W. Phang, "Emergent Leadership in Virtual Collaboration Settings: A Social Network Analysis Approach", Long Range Planning 44(5-6), 2011, pp. 421-439.

[32] Toivonen, M., and T. Tuominen, "Emergence of innovations in services", Service Industries Journal 29(7), 2009, pp. 887-902.

[33] Trainor, K.J., J. Andzulis, A. Rapp, and R. Agnihotri, "Social Media Technology Usage and Customer Relationship Performance: A Capabilities-based Examination of Social CRM", Journal of Business Research, 2014.

[34] Vargo, S.L., and R.F. Lusch, "Evolving to a New Dominant Logic for Marketing", Journal of Marketing 68(1), 2004, pp. 1-17.

[35] Vargo, S.L., and R.F. Lusch, "Service-dominant Logic: Continuing the Evolution", Journal of the Academy of Marketing Science 36(1), 2008, pp. 1-10.

[36] Vivek, S.D., S.E. Beatty, and R.M. Morgan, "Customer Engagement: Exploring Customer Relationships Beyond Purchase", The Journal of Marketing Theory and Practice 20(2), 2012, pp. 122-146.

[37] Xie, K., Y. Wu, J. Xiao, and Q. Hu, "Value Co-creation between Firms and Customers: The Role of Big Data-based Cooperative Assets", Information and Management 53(8), 2016, pp. 1034-1048.

[38] Ye, H. (Jonathan), and A. Kankanhalli, "User Service Innovation on Mobile Phone Platforms: Investigating Impacts of Lead Userness, Toolkit Support, and Design Autonomy", MIS Quarterly, 2018.

[39] Yin, R.K., Case study research: design and methods, Sage Publications, California, 2009. 